\title{
Cupriavidus yeoncheonense sp. nov., isolated from soil of ginseng
}

\author{
Priyanka Singh • Yeon-Ju Kim • Ngoc-Lan Nguyen • \\ Van-An Hoang • Johan Sukweenadhi • \\ Mohamed El-Agamy Farh • Deok-Chun Yang
}

Received: 30 September 2014/ Accepted: 23 December 2014/Published online: 19 February 2015

(c) Springer International Publishing Switzerland 2015

\begin{abstract}
A novel bacterial strain, DCY86 ${ }^{\mathrm{T}}$ (=KCTC $42053^{\mathrm{T}}=\mathrm{JCM} 19890^{\mathrm{T}}$ ) was isolated from soil of a ginseng field in Yeoncheon province $\left(38^{\circ} 04^{\prime} 00^{\prime \prime} \mathrm{N}\right.$ $\left.126^{\circ} 57^{\prime} 00^{\prime \prime} \mathrm{E}\right)$, Republic of Korea using a serial dilution method. Strain DCY $86^{\mathrm{T}}$ was observed to be Gram-stain negative, strictly aerobic, to grow optimally at 25-30 ${ }^{\circ} \mathrm{C}$, at $\mathrm{pH} 7-7.5$ and on tryptic soya agar medium. The cells were found to be sensitive to ceftazidine and tetracycline. Based on $16 \mathrm{~S}$ rRNA gene sequence comparisons, strain $\mathrm{DCY}^{\mathrm{T}}{ }^{\mathrm{T}}$ was found to be most closely related to Cupriavidus basilensis LMG $18990^{\mathrm{T}}$ (98.48\%), Cupriavidus numazensis LMG $26411^{\mathrm{T}}$ (98.34\%), Cupriavidus pinatabonesis KCTC $22125^{\mathrm{T}}$
\end{abstract}

Electronic supplementary material The online version of this article (doi:10.1007/s10482-014-0369-z) contains supplementary material, which is available to authorized users.

P. Singh $\cdot$ Y.-J. Kim $\cdot$ N.-L. Nguyen ·

V.-A. Hoang - D.-C. Yang

Department of Oriental Medicinal Material and

Processing, College of Life Science, Kyung Hee

University, Seocheon-dong, Giheung-gu,

Gyeonggi-do, Yongin-si 446-701, Republic of Korea

Y.-J. Kim ( $ه)$ - J. Sukweenadhi · M. E.-A. Farh ·

D.-C. Yang ( $\square)$

Graduate School of Biotechnology, Ginseng Genetic

Resource Bank, College of Life Science, Kyung Hee

University, Yongin 446-701, Republic of Korea

e-mail: yeonjukim@khu.ac.kr

D.-C. Yang

e-mail: deokchunyang@yahoo.co.kr
(98.34\%) and Cupriavidus laharis KCTC $22126^{\mathrm{T}}$ $(98.00 \%)$. The $\mathrm{G}+\mathrm{C}$ content was determined to be $64.23 \mathrm{~mol} \%$. The only isoprenoid quinone detected in strain DCY86 ${ }^{\mathrm{T}}$ was ubiquinone Q-8. The major polar lipids were identified as diphosphatidylglycerol, phosphtidylethanolamine, phosphatidylglycerol, unidentified aminophosphoglycolipids and unidentified phospholipids. The major fatty acids were identified as $\mathrm{C}_{16: 0}$ summed feature $3\left(\mathrm{C}_{16: 1} \omega 7 \mathrm{c} / \omega 6 \mathrm{c}\right.$ and/or iso- $\mathrm{C}_{15 \text { :0 }}$ $2-\mathrm{OH})$ and summed feature $8\left(\mathrm{C}_{18: 1} \omega 7 \mathrm{c}\right.$ and/or $\mathrm{C}_{18: 1}$ $\omega 6 \mathrm{c})$. These data support the affiliation of strain $\mathrm{DCY}^{\mathrm{T}}{ }^{\mathrm{T}}$ to the genus Cupriavidus. Strain DCY86 ${ }^{\mathrm{T}}$ was also found to be able to solubilize phosphate and produce siderophores. The results of physiological and biochemical tests enabled strain DCY $86^{\mathrm{T}}$ to be differentiated genotypically and phenotypically from the recognized species of the genus Cupriaividus. Therefore, the novel isolate can be considered to represent a novel species, for which the name Cupriavidus yeoncheonense sp. nov. is proposed here. The type strain is $\operatorname{DCY}^{\mathrm{T}}{ }^{\mathrm{T}}\left(=\mathrm{KCTC} 42053^{\mathrm{T}}=\mathrm{JCM} 19890^{\mathrm{T}}\right)$.

Keywords Cupriavidus yeoncheonense . Proteobacteria · Ginseng · Polyphasic taxonomy

\section{Introduction}

The genus Ralstonia was proposed in 1995 to accommodate the misplaced species Burkholderia pickettii, 